\title{
Adherence to complementary gender stereotypes and attitudes towards male infidelity
}

\author{
Achille Vicky DZUETSO MOUAFO ${ }^{1}$, Hermann Kevin EKANGO NZEKAIH ${ }^{2}$, Stéphane SOGBOU LOYEM ${ }^{3}$ \\ ${ }^{I}$ Department of Philosophy/Psychology, University of Maroua, Cameroon \\ ${ }^{2}$ Department of Philosophy-Psychology-Sociology, University of Dschang, Cameroon \\ 3International Relations Institute of Cameroon, University of Yaoundé II, Cameroon
}

\begin{abstract}
This study assesses the effect of adherence to complementary gender stereotypes on attitudes toward male infidelity. It aims to contribute to the literature on the implication of stereotypes in the maintenance of disproportionate social and sexual conditions (Eagly \& Wood, 1999; Jost \& Kay, 2005; Kahalon, 2018). It tests the hypothesis that adherence to complementary gender stereotypes has an effect on attitudes towards male infidelity. 87 students of both sexes, enrolled in the psychology unit of the University of Dschang (Cameroon), were selected to participate voluntarily in the study. Their age varies between 15 and 41 years $(M .=21.44 ; S D=4.71)$. The procedure of data collection was inspired by Jost and Kay's work (2005). Participants responded to measures of complementary gender stereotypes, simple gender stereotypes, and attitudes toward male infidelity. The data collected provides empirical support for the hypothesis of the study. Indeed, adherence to complementary gender stereotypes positively affects attitude towards male infidelity $(\beta=16.67 ; t=3.58 ; p<.02)$, just as much as adherence to simple gender stereotypes $(\beta=19.23 ; t=5.29 ; p<.01)$. It is concluded that men and women mutually participate in maintaining disproportionate social and sexual conditions.
\end{abstract}

Keywords: gender, complementary gender stereotypes, simple gender stereotypes, infidelity, attitude towards male infidelity.

\section{INTRODUCTION}

$I^{2}$ nfidelity is the engagement in a sexual relationship other than a two-person or monogamous relationship (Mark et al., 2011). It is, therefore, a major problem for couple relationships, due to the intrusion of a third person into the relational dyad (Ojedokun, 2015). Survey data shows that around $50 \%$ of people are inclined to engage in some form of infidelity at some point of their married life (Drigotas et al., 1999). This behavior generates distress, torment, and sometimes it is the cause of the complete breakdown of romantic relationships. It is seen as a breach of trust or a breakdown in the understanding of monogamy, because it tramples on the principle of sexual exclusivity (Pittman et al., 1995). It involves a certain number of activities: extramarital affair, inclusive sex, emotional bonds beyond friendships, digital romantic and inclusive touching relationships (Zare, 2011; Mehrinejad \& Shahabi, 2018). It depends on the type of relationship that exists between individuals and varies between cultures.

In a cross-cultural study, Yeniceri and Kokdemir (2006) indicate that there are many reasons why infidelity occurs. Specifically, these authors reveal that: 1) men place more emphasis on the causal role of seduction than women; 2) women tend to perceive the social environment as a major cause of this phenomenon more than men; 3) seduction is considered as the main source of infidelity when it is men who are involved in this phenomenon; and 4) if women are to be blamed for infidelity, then the legitimacy of that blame is seen as a reasonable cause for doing so. According to Lewandowski and Ackerman (2006), lack of basic needs satisfaction and self-empowerment are additional predictors of infidelity. These authors come to the conclusion that sex, relationships' length, need for development and selfemancipation contribute to a considerable increase in infidelity behaviors.

Several models provide theoretical explanations of infidelity behaviors. The first is Bandura's (1978) social learning model. It emphasizes observation in a social environment. It indicates that, by observing behavior patterns, we tend to imitate or match our behaviors with observed behaviors (Mihalic \& Elliott, 2005). In this perspective, individuals learn and understand attitudes and behaviors as a result of the social interactions they have with other people in their environment (Strong et al., 2005). According to Bandura (1978), human nature is formed through the bonds between individuals, and learning by observing others is of paramount importance in this process, compared to learning by oneself. In this perspective, a study conducted within the framework of this model reveals that by observing infidelity behavior through peer groups, media or family, individuals come to consider such behavior as acceptable in their relationships (Strong et al., 2005).

The second model refers to evolutionary theory (Eagly \& Wood, 1999). The emphasis is on gender differences. In fact, studies from this perspective report that the differences in attitudes and behaviors related to sexual relations are impacted by the various obstacles related to reproductive success that men and women have been confronted to during their earlier lives (Eagly \& Wood, 1999; Sprecher et al., 1998). For example, it is considered that gender differences in infidelity can be explained by gender differences in the minimum parental investment required to accompany a child to maturity. In this logic, one can observe that the costs of male infidelity are relatively low. Indeed, men can cheat and potentially have other offspring as a result of their infidelity. 
They are also likely to decide to take care of more than one partner at the same time and therefore increase the likelihood of having even more offspring in their lifetime, without having to endure the physical cost of pregnancies for example. It is quite the opposite when it comes to women, since the costs of infidelity are much higher for them. The reason is that, if infidelity is sometimes connoted with pregnancy, then they will, at a minimum, have to endure a gestation period of nine months, face the considerable risks of childbirth, the demands of breastfeeding, and the possibility of educating their children alone, in cases where their fathers do not assume their parental responsibilities (Broady \& Hickman, 2007).

The third theoretical model commonly used to explain infidelity behaviors relates to social roles (Eagly, 1987). It is the theoretical framework of this study. It suggests that both men and women conform to gender stereotypes due to their association with expected social roles. Indeed, social role theory suggests that both men and women are able to adapt to the environmental conditions. As a result, their behavior is consistent with existing social contexts rather than biological influences. In traditional social considerations, men work outside the home, while women do so inside the home. As a result, in their role, men have learned to be dominant, independent, sexually active, autocratic and less engaged in exclusive relationships (Eagly \& Wood, 1999). In contrast, women have learned to engage more in exclusive relationships, are less motivated for extramarital affairs and more cooperative. In this logic, the theory of social roles argues that these different roles lead men and women to think and behave differently in romantic relationships. For example, due to the fact that men are used to being independent and familiar, they tend to be more reluctant to engage in marriage, a social institution that involves a cooperative life between partners. In contrast, women are more concerned with developing intimacy in their relationships and have an overall concern for exclusive relationships. Therefore, in intimate relationships, they are more engaged than their male partners (Vogel et al., 2003). These observations allow us to perceive the central role of gender stereotypes on the attitude of individuals towards infidelity.

The concept of gender has several meanings. The meaning commonly used to designate it is that of the social and cultural construction of male and female identity (Claudine, 2009). In the United States, this concept is used to refer to the social, and therefore unnatural, character of differentiations based on sex. In this wake, gender refers to social and cultural differences acquired by men and women and which are likely to change in accordance with changes in social relations. Gender stereotypes, on the other hand, generally refer to any linguistic, attitudinal or behavioral, pejorative or partisan representation of one or the other sex, tending to associate specific roles, behaviors, characteristics or particular attributes with people, according to their sex, without any link with their individuality. In this vein, it is observed that in the media, men and women have a socially recognized type of model (Faits et Gestes, 2007). Indeed, women are conceived as having to be beautiful, slim, young and mature. Their behaviors are believed to be characterized by gentleness, maternal feeling, support, and sexual availability. On the other hand, the type of men' model is linked to the physical framework because it obeys an imperative: to be handsome and muscular. In their ways of being and doing, they must be dominant, protective, rational and competitive. Consistent with these role expectations, they are more concerned with maintaining their autonomy (Vogel et al., 2003), tend to avoid exclusive engagement, and have lower expectations for intimacy (Tornstam, 1992). They are also more likely than women to cheat in their intimate relationships (Michael et al., 1995), as evidenced by the observations of a survey which reports that 20 to $40 \%$ of them, compared to 14 to $25 \%$ of women in the general population admit to having had extramarital sex at least once in their life (Simard, 2016).

There are gender differences in the attitudes and behaviors of individuals towards intimate relationships (Oliver \& Hyde, 1993). Despite the fact that the magnitude of these differences is quite small, it still support the widely held observations that men have more sexual partners than women. So, although a gender difference in attitudes towards cheating has been revealed, its magnitude is very small, with an effect size of .29. Oliver and Hyde (1993) note that there is more of a similarity rather than a gender difference in the attitudes of individuals towards infidelity. According to these authors, gender stereotypes tend to increase the differences between men and women in attitude towards infidelity, while in fact, they think and behave the same towards this social phenomenon.

The literature relating to the role of gender stereotypes on the attitude towards infidelity presents inadequacies on three levels: 1) it hardly concerns the attitude of individuals towards male infidelity, yet recognized as being more socially accepted and widespread than its female counterpart (Simard, 2016); 2) it did not consider the impact of adherence to complementary gender stereotypes on attitudes towards male infidelity; and 3) it is not concerned with whether or not there is a gender difference in attitude towards male infidelity when individuals adhere to complementary gender stereotypes or simple gender stereotypes. Indeed, in implicit personality theory (Rosenberg et al., 1968), men are generally stereotyped as competent, authoritarian, sexually active, independent and focused on inclusive relationships, unlike women who, on the other hand, are generally stereotyped as sensitive, sociable, interdependent and focused on exclusive relationships (Deaux \& Lewis, 1984; Eagly \& Steffen, 1984; Langford \& MacKinnon, 2000; Williams \& Best, 1982 Sakalli-Uğurlu et al., 2018). Research on the concept of gender stereotypes shows that they can, in certain cases, be complementary (Jost \& Kay, 2005; Kay \& Jost, 2003). In this sense, they refer to the fact that each sexual category is seen to possess strengths that balance its own weaknesses and complement the 
strengths of the other category. This complementarity of the gender stereotype makes social living conditions more acceptable, and affects the attitudes of individuals towards social and sexual privileges (Jost \& Kay, 2005).

The experimental work carried out on complementary gender stereotypes reveals a prevalence of social and professional roles held by men and women (Kahalon et al., 2018). Therefore, their stereotypical attributes are derived from information about their status and roles (Eagly \& Steffen, 1984). This observation is reinforced by other studies in which individuals attribute sociability characteristics, but without competence to employees, taking into account only the statuses and roles assigned to them (Conway et al., 1996; Glick et al., 1995; Hoffman \& Hurst, 1990; Ridgeway, 2001). Additionally, some of these researches comes to the conclusion that in some contexts, people tend to stereotype members of high status groups as competent but non-sensitive and members of low status groups as very sensitive but incompetent. Following these empirical works, studies on complementary gender stereotypes report that attitudes towards men and women are ambivalent (Glick \& Fiske 1996; 2001). In this wake, male and female stereotypes include both very favorable and unfavorable attributes. Sexism can be included in this framework because it is seen as a strange mixture of hostility and benevolence (Jost \& Kay, 2005).

To capture ambivalent sexism, an instrument assessing hostile and benevolent sexisms as distinct, but related constructs, has been constructed and validated (Glick \& Fiske, 1996). In a study carried out in several countries, observations made show that women are as likely as men to assume ambivalent forms of gender characteristics (Glick et al., 2000). In each of these countries, the average sexism rates of men and women were strongly and positively correlated with each other, and hostile and benevolent sexisms were at their highest in societies where levels of gender equality and female empowerment were reduced. Glick and Fiske (2001) concluded that benevolent, ambivalent or even complementary gender characteristics may play an important role in justifying gender differences in privilege. This is because the ambivalent or complementary stereotypes attributed to men and women serve two important functions in maintaining disproportionate social and sexual conditions (Jackman, 1994). First, they treat each gender category as essentially well suited to fill the positions and roles that are prescribed for it by society (Hoffman \& Hurst, 1990; Kahalon et al., 2018). Second, they prevent women from completely withdrawing from social and sexual conditions, in a societal context where it is presumed that men are competent while women are not (Glick \& Fiske, 2001; Kahalon et al., 2018). Based on these findings, this research asks whether complementary gender stereotypes are able, like simple gender stereotypes, to affect the attitudes of individuals towards male infidelity, which is mainly practiced by male in all societies (Simard, 2016), and which, conventionally, constitute a privilege granted to them. Previous studies have not addressed this concern. This is why this research is dedicated to it. It seeks to answer the following research question: What is the effect of adherence to complementary gender stereotypes on individuals' attitudes towards male infidelity? The answer to this question constitutes the main contribution of this work to the literature on the implication of stereotypes in the maintenance of disproportionate social and sexual conditions (Eagly \& Wood, 1999; Hoffman \& Hurst, 1990; Jost \& Kay, 2005; Kahalon, 2018; Spreche et al., 1998).

\section{HYPOTHESES}

This study tests the hypothesis that adherence to complementary gender stereotypes has an effect on attitudes towards male infidelity. In detail, it is expected that: 1) strong adherence to complementary gender stereotypes will positively affect attitudes towards male infidelity; 2) there is no difference between men and women on the (positive) attitude towards male infidelity; and 3) adherence of men and women to complementary gender stereotypes and simple gender stereotypes does not affect the positive attitude towards male infidelity.

\section{METHOD}

\section{Participants}

87 students of both sexes, enrolled in the psychology unit of the University of Dschang (Cameroon) have given their consent to participate voluntarily to the study. Their age varies between 15 and 41 years $(M .=21.44 ; \mathrm{SD}=4.71)$. They were randomly divided into two groups according to the experimental conditions (50 under the condition of exposure to complementary gender stereotypes and 37 under the condition of exposure to simple stereotypes). They were told that the study aimed to measure their intergroup behaviors. Guarantees of anonymity and confidentiality were given to them regarding the use of the information they would provide during the experiment for strictly scientific purposes.

\section{Experimental material and procedure}

The data collection procedure of this study is based on Jost and Kay' work (2005). Thus, the administration of the experimental material is made in two phases, depending on the experimental conditions. In each condition, participants are invited to carefully read the information that is reported on the instrument of data collection, and to give their opinion. The experimenters presented to the participants of the first group an instrument on which complementary characteristics of gender are given (exposure to complementary gender stereotypes). It was designed based on the indicators of complementary stereotypes proposed by Jost and Kay (2005). It is made up of five items highlighting the favorable attributes specific to male category, but which tend to complement the weaknesses of female category. For example, items 1 and 2 of this instrument respectively propose that: In general, men are not serious while women are; and In society, men are competitive, but women are cooperative. Participants rate their degree of agreement or disagreement with these 
statements on a 7-points Likert scale, ranging from 1 (strongly disagree) to 7 (strongly agree). The researchers then administered the Attitude towards Male Infidelity Scale. It is a measurement method consisting of 4 items, adapted from the attitude towards infidelity scale (Whatley, 2006). It does not have a reversed coded item. For instance, items 1 and 3 are respectively formulated as follows: In general, a man's infidelity is a natural thing; and I wouldn't mind if I found out that a man has another partner. This measurement has a good internal consistency index $(\alpha=.72$ for the global scale and $\alpha=$ .70 for the measurement of male infidelity in the situation of exposure to complementary stereotypes). Participants indicate their degree of agreement or disagreement with items on a 7points Likert scale, ranging from 1 (strongly disagree) to 7 (strongly agree). The higher the participants' scores, the more positive their attitude towards male infidelity.

The researchers administered an instrument of data collection comprising five simple male gender's characteristics to the second group of participants (condition of exposure to simple gender stereotypes). These five (5) statements were formulated by simplifying the items on complementary gender characteristics. Items 1 and 2 are respectively worded as follows: In general, men are not serious; and In society, men are competitive. For each statement, participants rated their degree of agreement or disagreement on a 7-points Likert scale, ranging from 1 (strongly disagree) to 7 (strongly agree). Next, participants were administered the Attitude towards Male Infidelity Scale presented in the previous paragraph. In the context of this second experimental condition, this measurement also has a good reliability index $(\alpha=.75)$.

\section{RESULTS}

The presentation of the results of this study is done in two phases. The first dwells on descriptive and correlational analyzes between the variables of the study, taking into account the different gender categories. These statistics are represented by M (means) and SD (Standard deviations) for the descriptions and by the $\mathrm{r}$ index for the correlations. The second is devoted to the analyzes of the linear regression between the variables, by also taking the different gender categories into account. These analyzes are summarized by the standardized coefficient beta $(\beta)$ and its index $t$. Complementary analyzes relating to the comparison of means between the different gender categories on attitude towards male infidelity are also carried out. These can be seen through the F-index of the ANOVA means comparison test.

\begin{tabular}{|c|c|c|c|c|c|c|}
\hline \multirow[b]{2}{*}{ Measures } & \multicolumn{2}{|c|}{$\begin{array}{c}\text { General trends } \\
(\mathrm{N}=50)\end{array}$} & \multicolumn{2}{|c|}{$\begin{array}{l}\text { Women } \\
(\mathrm{N}=28)\end{array}$} & \multicolumn{2}{|c|}{$\begin{array}{c}\text { Men } \\
(\mathrm{N}=22)\end{array}$} \\
\hline & M (É.-T.) & $r(p)$ & M (É.-T.) & $r(p)$ & M (É.-T.) & $r(p)$ \\
\hline \multicolumn{7}{|l|}{$\begin{array}{c}\text { Exposure to complementary } \\
\text { stereotypes }\end{array}$} \\
\hline 1. Complementary stereotypes & $19,62(5.98)$ & - & $19.46(5.81)$ & - & $22.09(5.87)$ & - \\
\hline 2. Attitude towards male infidelity & $25,46(7.59)$ & $.25(<.05)$ & $24.75(6.80)$ & $.28(<.05)$ & $28,27(8.33)$ & $.30(<.05)$ \\
\hline Exposure to simple stereotypes & \multicolumn{2}{|c|}{$(\mathrm{N}=37)$} & \multicolumn{2}{|c|}{$(\mathrm{N}=19)$} & \multicolumn{2}{|c|}{$(\mathrm{N}=18)$} \\
\hline 1. Simple stereotypes & $22,35(5.84)$ & - & $21,58(6.50)$ & - & $23,17(5.10)$ & - \\
\hline 2. Attitude towards male infidelity & $27,54(7.52)$ & $.37^{*}(<.02)$ & $26,42(7.64)$ & $.29(<.05)$ & $28,72(7.42)$ & $.46^{*}(<.05)$ \\
\hline \multicolumn{7}{|c|}{ Note: Significant correlation at .05} \\
\hline
\end{tabular}

This table reveals that the general tendency of participants to adhere to complementary gender stereotypes is high $(\mathrm{M}=$ 19.62; $\mathrm{SD}=5.98)$. This adherence is also observed for simple gender stereotypes $(M=22.35 ; \mathrm{SD}=5.84)$. The attitude of participants towards male infidelity is positive, both for those who have been exposed to complementary stereotypes $(\mathrm{M}=$ 25.46; $\mathrm{SD}=7.59)$ and those who have been exposed to simple gender stereotypes $(\mathrm{M}=27.54 ; \mathrm{SD}=7.52)$. These general trends in descriptive statistics are in line with research hypothesis 1 . They are verified through descriptive analyzes made according to gender categories. Thus, we observe that women adhere to both complementary gender stereotypes ( $\mathrm{M}$ $=19.46 ; \mathrm{SD}=5.81)$ and simple gender stereotypes $(\mathrm{M}=$ 21.58; $\mathrm{SD}=6.50$ ). They also have a positive attitude towards male infidelity, as much when they adhere to complementary gender stereotypes $(M=24.75 ; \mathrm{SD}=6.80)$ as when they agree with simple gender stereotypes $(\mathrm{M}=26.42 ; \mathrm{SD}=7.64)$. Men strongly adhere to complementary gender stereotypes $(\mathrm{M}=$ 22.09; $\mathrm{SD}=5.87)$ and simple gender stereotypes $(\mathrm{M}=23.17$; $\mathrm{SD}=5.10$ ). Their attitude towards male infidelity is positive both for those who adhere to complementary gender stereotypes $(\mathrm{M}=28.07 ; \mathrm{SD}=8.23)$ and those who agree with simple gender stereotypes $(M=23.17 ; \mathrm{SD}=5.10)$. These partial analyzes are in line with research hypotheses 2 and 3.

The correlation analyzes shed light on the various observations made in the previous paragraph. They indicate that the general tendency of the link between the variables is positive both for participants exposed to complementary gender stereotypes $(r=.25 ; \mathrm{p}<.05)$ and those exposed to simple gender stereotypes $(r=.37 * ; p<.03)$. These results provide an empirical support to research hypothesis 1 . Taking 
into account the differences between categories, one can observe that among women, the relationship between the variables is positive among participants exposed to complementary gender stereotypes $(r=.28 ; \mathrm{p}<.05)$ and those exposed to simple gender stereotypes $(r=.29 ; \mathrm{p}<.05)$. Among men, this relationship is also positive both for participants subjected to complementary gender stereotypes $(r=.30 ; p$ $<.05)$ and those exposed to simple gender stereotypes $(r=.46$ $* ; \mathrm{p}<.05)$. These different correlations between the variables provide empirical support for research hypotheses 2 and 3 . The regression analyzes below also goes in this direction.

\begin{tabular}{|c|c|c|c|c|c|c|c|c|c|c|c|c|}
\hline \multirow[b]{2}{*}{ Mesures } & \multicolumn{4}{|c|}{$\begin{array}{c}\text { General trends } \\
(\mathrm{N}=50)\end{array}$} & \multicolumn{4}{|c|}{$\begin{array}{l}\text { Women } \\
(\mathrm{N}=28)\end{array}$} & \multicolumn{4}{|c|}{$\begin{array}{c}\text { Men } \\
(\mathrm{N}=22)\end{array}$} \\
\hline & $\beta$ & S.E & $t$ & $p$ & $\beta$ & S.E & $t$ & $p$ & $\beta$ & S.E & $t$ & $p$ \\
\hline $\begin{array}{c}\text { Exposure to } \\
\text { complementary } \\
\text { stereotypes }\end{array}$ & & & & & & & & & & & & \\
\hline $\begin{array}{l}\text { 1. Complementary } \\
\text { stereotypes }\end{array}$ & $\begin{array}{l}19 . \\
23\end{array}$ & 3.63 & 5.29 & .00 & 18.15 & 4.45 & 4.07 & .00 & 18.61 & 6.89 & 2.70 & .01 \\
\hline $\begin{array}{l}\text { Exposure to simple } \\
\text { stereotypes }\end{array}$ & \multicolumn{4}{|c|}{$(\mathrm{N}=37)$} & \multicolumn{4}{|c|}{$(\mathrm{N}=19)$} & \multicolumn{4}{|c|}{$(\mathrm{N}=18)$} \\
\hline 1. Simple stereotypes & $\begin{array}{l}16 . \\
67 \\
\end{array}$ & 4.65 & 3.58 & .01 & 18.88 & 6.11 & 3.09 & .00 & 13.18 & 7.65 & 2.07 & .05 \\
\hline
\end{tabular}

In this table, the data reveal that the general trend in the strength of the effect of complementary stereotypes on attitude towards male infidelity is positive and significant $(\beta=$ $19.23 ; \mathrm{t}=5.29 ; \mathrm{p}<.01)$. This is also observed for the impact of simple gender stereotypes on attitudes towards male infidelity $(\beta=16.67 ; \mathrm{t}=3.58 ; \mathrm{p}<.02)$. These analyzes provide additional support for research hypothesis 1 . By taking into account the differences between categories, the results show that among women, the complementary gender stereotype positively and significantly affects the attitude towards male infidelity $(\beta=18.15 ; \mathrm{t}=4.07 ; \mathrm{p}<.01)$. Their adherence to simple gender stereotypes also positively and significantly affects their attitude towards male infidelity $(\beta=18.88 ; \mathrm{t}=$ $3.09 ; \mathrm{p}<.01)$. These results are confirmed among men, because we observe that their adherence to complementary gender stereotypes has a positive and significant effect on their attitude towards male infidelity $(\beta=18.61 ; \mathrm{t}=2.70 ; \mathrm{p}<$ .02). Likewise, when they adhere to simple gender stereotypes, it positively increases their attitude towards male infidelity $(\beta=13.18 ; \mathrm{t}=2.07 ; \mathrm{p}<.05)$. These linear regression statistics also provide empirical support for research hypotheses 2 and 3 .

In order to shed light on predictions on the non-differentiation of attitudinal dispositions relating to male infidelity between categories, additional analyzes consisting on the ANOVA means comparison test were carried out. It reveals that women and men exposed to complementary gender stereotypes (f (50 $1)=2.28 ; \mathrm{p}>.05)$, as well as those who were exposed to simple gender stereotypes (f $(371)=1.04 ; p>.05)$ do not differ in their attitude towards male infidelity. These analyzes also indicate that the women $(\mathrm{f}(472)=.97 ; \mathrm{p}>.05)$ and men ( $\mathrm{f}$ $(402)=.68 ; p>.05)$ of the two experimental groups do not differ either in their attitude towards male infidelity. The attitudes towards male infidelity of women exposed to complementary gender stereotypes and men exposed to simple gender stereotypes are also not different (f $\left(\begin{array}{ll}46 & 3\end{array}\right)=.97$; $\mathrm{p}>.05)$. This non-difference is also perceived between men exposed to complementary gender stereotypes and women exposed to simple gender stereotypes (f (42 3$)=.71 ; p>.05)$. Overall, we observe a non-difference between the attitudes towards male infidelity among participants exposed to complementary gender stereotypes and those exposed to simple gender stereotypes (f $(874)=.90 ; p>.05$ ). These comparison-of-means analyzes provide empirical support for research hypotheses 2 and 3, hence the conclusion that adherence to complementary gender stereotypes has an effect on attitudes towards male infidelity.

\section{DISCUSSION}

This research defended the thesis that adherence to complementary gender stereotypes has an effect on attitudes towards male infidelity, a behavior that appears to be conventionally accepted and predominantly practiced (Simard, 2018). The data collected from the study provides empirical support for the prediction made. In fact, it has been observed that: 1) strong adherence to complementary gender stereotypes positively affects attitudes towards male infidelity; 2) there is no difference between men and women in the positive attitude towards male infidelity; and 3) adherence of men and women to complementary and simple gender stereotypes does not affect the positive attitude towards male infidelity. These results provide support for the idea that complementary gender stereotypes play a key role in maintaining disproportionate social and sexual conditions (Eagly \& Wood, 1999; Hoffman \& Hurst, 1990; Jost \& Kay, 2005; Kahalon, 2018 ; Sprecher et al., 1998). As a reminder, when complementary stereotypes are attributed to men and women, they fulfill two important roles in maintaining these 
conditions of inequality between the two sexes (Jackman, 1994). First, they treat each gender category as essentially well suited to fill the positions and roles that are prescribed by society (Hoffman \& Hurst, 1990; Kahalon et al., 2018). Then, they prevent women from completely withdrawing from social and sexual conditions, in a societal context where men are presumably competent, while women are not (Glick \& Fiske, 2001; Kahalon et al., 2018).

The present study, through its results, sheds light on the impact of complementary gender stereotypes on the approval of male infidelity. Indeed, we observe that the more the participants adhere to these stereotypes, the more they are motivated to perceive male infidelity as natural, fair and acceptable. These results agree with the observations of the literature on the role of complementary gender stereotypes; the latter being renowned for their contribution to maintaining the status quo in men and women' relations (Jost \& Kay, 2005). These results can also be understood with the explanations of the system justification theoretical framework. This theory proposes that the belief that in society each group has certain advantages and faces certain disadvantages increases the feeling that sexual arrangements, as a whole, are right, natural and legitimate. The reason is that beyond adhering to simple gender stereotypes to rationalize genderspecific roles in households, complementary gender stereotypes serve to justify and maintain the perceived advantages of men (Jost \& Kay, 2005). That is the reason why both gender categories are strongly motivated to accept male infidelity which is a social privilege for men.

The results of this study are consistent with the researches on social roles, which argue that role differences lead men and women to think and behave differently towards intimate relationships. They push women to be more concerned by the intimate domain in their relationships, unlike men (Vogel et al., 2003); which, therefore, leads people of both genders to become less engaged in challenging male infidelity, as it is the case with the participants of this study. Likewise, from this theoretical perspective, one can suggest that men are more concerned with maintaining their autonomy; tend to avoid engaging in an exclusive relationship; have low expectations for intimacy and are more likely to cheat on their partners than women (Michael et al., 1995; Tornstam, 1992). These elements may explain the motivation to approve male infidelity behaviors. This mutual support of men and women for male infidelity reveals, ultimately, the degree to which these two categories participate in maintaining gender inequalities and the universally shared paternalistic system.

\section{REFERENCES}

[1] Bandura, A. (1978). Social Learning Theory. Journal of Communication, 28(3), 12-29.

[2] Claudine, L. (2009). Les stéréotypes sexistes, outils de discriminations des femmes et des hommes, Intervention lors de l'après-midi d'étude organisée par le CEFA asbl et l'Université des Femmes asbl. France.

[3] Conway, M., Pizzamiglio, M. T., \& Mount, L. (1996). Status, communality, and agency: Implications for stereotypes of gender and other groups. Journal of Personality and Social Psychology, 71, 25-38.

[4] Deaux, K., \& Lewis, L. L. (1984). Structure of gender stereotypes: Interrelationships among components and gender label. Journal of Personality and Social Psychology, 46, 991-1004.

[5] Drigotas, S. M., Safstrom, C. A., \& Gentilia, T. (1999). An investment model prediction of dating infidelity. Journal of Personality and Social Psychology, 77, 509-524.

[6] Eagly, A. H. (1987). Sex differences in social behavior: A socialrole interpretation. Lawrence Erlbaum Associates.

[7] Eagly, A. H., \& Steffen, V. (1984). Gender stereotypes stem from the distribution of women and men into social roles. Journal of Personality and Social Psychology, 46, 735-754.

[8] Eagly, A. H., \& Wood, W. (1999). The origins of sex differences in human behavior: Evolved dispositions versus social roles. American Psychologist, 54, 408-423.

[9] Faits \& Gestes (2007). Débats et Recherches en Communauté française Wallonie-Bruxelles. 22 : Les jeunes face au sexisme à la télévision. France.

[10] Glick, P., \& Fiske, S. T. (1996). The Ambivalent Sexism Inventory: Differentiating hostile and benevolent sexism. Journal of Personality and Social Psychology, 70, 491-512.

[11] Glick, P., \& Fiske, S. T. (2001). An ambivalent alliance: Hostile and benevolent sexism as complementary justifications for gender inequality. American Psychologist, 56, 109-118.

[12] Glick, P., Fiske, S. T., Mladinic, A., Saiz, J., Abrams, D., Masser, B., et al. (2000). Beyond prejudice as simple antipathy: Hostile and benevolent sexism across cultures. Journal of Personality and Social Psychology, 79, 763-775.

[13] Glick, P., Wilk, K., \& Perreault, M. (1995). Images of occupations: Components of gender and status in occupational stereotypes. Sex Roles, 32, 565-582.

[14] Hoffman, C., \& Hurst, N. (1990). Gender stereotypes: Perception or rationalization? Journal of Personality and Social Psychology, 58, 197-208.

[15] Jackman, M. R. (1994). The velvet glove: Paternalism and conflict in gender, class, and race relations. University of California Press.

[16] Jost, J. T., \& Kay, A. C. (2005). Exposure to benevolent sexism and complementary gender stereotypes: Consequences for specific and diffuse forms of system justification. Journal of Personality and Social Psychology, 88 (3), 498-509.

[17] Kahalon, R., Shnabel, N., \& Becker, J. C. (2018). Positive stereotypes, negative outcomes: reminders of the positive components of complementary gender stereotypes impair performance in counter-stereotypical tasks. British Journal of Social Psychology, 52(2), 1-26.

[18] Kay, A. C., \& Jost, J. T. (2003). Complementary justice: Effects of "poor but happy" and "poor but honest" stereotype exemplars on system justification and implicit activation of the justice motive. Journal of Personality and Social Psychology, 85, 823-837.

[19] Langford, T., \& MacKinnon, N. J. (2000). The affective bases for the gendering of traits: Comparing the United States and Canada. Social Psychology Quarterly, 63, 34-48.

[20] Lewandowski, G., \& Ackerman, R. (2006). Something's Missing: Need Fulfillment and Self Expansion as Predictors of Susceptibility to Infidelity. The Journal of Social Psychology, 146(4), 389-403.

[21] Mark, K. P., Janssen, E., Milhausen, R. R. (2011). Infidelity in heterosexual couples: Demographic, Interpersonal, and Personality-related predictiors of extradyadic sex. Archives of Sexual Behavior, 40(5), 971-826.

[22] Mehrinejad, A., \& Shahabi, F., (2018). Prediction of attitude toward extramarital relationships based on impulsivity and personality trais. Journal of Reseach and Health, 8(6), 492-498.

[23] Michael, R.T., Gagnon, J. H., Laumann, E. O., \& Kolata, G. (1995). Sex in America: A definitive survey. Warner Books.

[24] Mihalic, S. W., \& Elliott, D. (2005). A social learning theory model of marital violence. In T. Chibucos \& R. Leite (Eds.), Readings in Family Theory (pp. 98). Sage Inc. 
[25] Ojedokun, I. M. (2015). Extramarital affair as correlate of reproductive health and home instability among couples in Ibadan, Nigeria. African Journal of Social Work, 5(2), 1-40.

[26] Oliver, M. B., \& Hyde, J. S. (1993). Gender differences in sexuality: A meta-analysis. Psychological Bulletin, 114, 25-51.

[27] Pittman, F., Pittman, \& Wagners T. (1995). Crises in infidelity. In N. Jacobson \& A. Gurman (Eds.), Clinical Handbook of Couple Therapy (pp.295). Guilford Press.

[28] Ridgeway, C. (2001). Gender, status, and leadership. Journal of Social Issues, 57, 637-655.

[29] Rosenberg, S., Nelson, C., \& Vivekananthan, P. S. (1968). A multidimensional approach to the structure of personality impressions. Journal of Personality and Social Psychology, 9, 283-294.

[30] Sakalli-Uğurlu, N., Türkoğlu, B., \& Kuzlak, A. (2018). How are women and men perceived? Structure of stereotypes in contemporary Turhey. Nesne Psikoloji Dergisi, 6(13), 309-336.

[31] Simard, M.-L. (2016). Caractéristiques sociodémographiques et psychologiques des individus gardant secrète leur infidélité. Thèse de doctorat défendue à l'Université Laval.

[32] Sprecher, S., Regan, P., \& McKinney, K. (1998). Beliefs about the outcomes of extramarital sexual relationships as a function of the gender of the 'cheating spouse.' Sex Roles, 38, 301-311.
[33] Strong, B., DeVault, C., \& Cohen, T. (2005). The marriage and family experience: Intimate relationships in a changing society (9th ed.). Wadsworth.

[34] Tornstam, L. (1992). Loneliness in marriage. Journal of Social and Personal Relationships, 9(2), 197-217.

[35] Vogel, D. L., Wester, S. R., Heesacker, M., \& Madon, S. (2003). Confirming gender stereotypes: A social role perspective. Behavioral Science, 48, 519-528.

[36] Whatley, M. (2006). Attitudes toward Infidelity Scale. Available at mwhatley@valdosta.edu.

[37] Williams, J. E., \& Best, D. L. (1982). Measuring sex stereotypes: A thirty-nation study. Sage.

[38] Yeneceri, Z., \& Kokdemir, D. (2006). University students' perceptions of, and explanations for, infidelity: The development of the infidelity questionnaire (INFQ). Social Behavior and Personality: An International Journal, 34(6), 639-650.

[39] Zare, B. (2011). Review of studies on infidelity. Singapore: IACSIT Press. 